\title{
HSP60 participates in the anti-glioma effects of curcumin
}

\author{
FENGCHEN BI $^{1 *}$, JUNYAN WANG $^{1 *}$, XIAOMIN ZHENG $^{1 *}$, JINGJING XIAO $^{1,2}$, CHAI ZHI $^{1,2}$, \\ JINHAI GU ${ }^{1}$, YUMEI ZHANG ${ }^{2}$, JUAN LI $^{3}$, ZHENHUA MIAO ${ }^{2}$, YIN WANG ${ }^{1,2}$ and YUNHONG LI ${ }^{1}$ \\ ${ }^{1}$ Ningxia Key Laboratory of Cerebrocranial Diseases, Ningxia Medical University; ${ }^{2}$ Basic Medical School of \\ Ningxia Medical University; ${ }^{3}$ School of Pharmacy, Ningxia Medical University, Yinchuan, Ningxia Hui 750004, P.R. China
}

Received July 21, 2020; Accepted December 1, 2020

DOI: $10.3892 /$ etm.2021.9637

\begin{abstract}
The chaperone protein heat shock protein 60 (HSP60) is considered a tumor promoter in several types of primary human tumors, where it orchestrates a broad range of survival programs. Curcumin (CCM) is well-established to exhibit several anticancer properties with an excellent safety profile. Our previous study showed that CCM suppresses extracellular HSP60 expression, which is typically released by activated microglia, and acts as an inflammatory factor by binding to Toll-like receptor 4 (TLR-4) on the cell membrane. The present study assessed whether CCM exerted its anti-neuroglioma effects on U87 cells via inhibition of HSP60/TLR-4 signaling, similar to that in microglia. The results demonstrated that CCM significantly inhibited the viability and invasive capacity of neuroglioma U87 cells as evidenced by a Cell Counting Kit- 8 assay. Western blotting and ELISA results showed that CCM decreased the expression of HSP60 and its transcriptional factor, heat shock factor 1, and reduced HSP60 release. Accordingly, TLR-4, as the target of HSP60, and its downstream signaling proteins myeloid differentiation primary response 88 (MYD88), NF- $\kappa \mathrm{B}$, inducible nitric oxide synthase and cytokines IL-1 $\beta$ and IL- 6 were downregulated by CCM. The expression levels of apoptotic factors associated with $\mathrm{NF}-\kappa \mathrm{B}$ activation, including TNF- $\alpha$ and caspase- 3 were increased in U87 cells by CCM treatment, while p53 expression, a tumor suppressor, was shown to be decreased. Based on the results of the present study, CCM may exert its anti-tumor effects in U87 cells by inhibiting the HSP60/TLR-4/MYD88/NF- $\mathrm{B}$ pathway and inducing tumor
\end{abstract}

Correspondence to: Professor Yunhong Li or Professor Yin Wang, Ningxia Key Laboratory of Cerebrocranial Diseases, Ningxia Medical University, Housheng Building, 1160 Shengli Street, Yinchuan, Ningxia Hui 750004, P.R. China

E-mail: liyunhong@hotmail.com

E-mail: yin-wang@hotmail.com

${ }^{*}$ Contributed equally

Key words: curcumin, heat shock protein 60/Toll-like receptor 4 signaling pathway, neuroglioma, U87 cells cell apoptosis. Thus, CCM may be used as a potential therapy for the clinical treatment of neuroglioma.

\section{Introduction}

Heat shock protein 60 (HSP60) is an evolutionarily conserved molecular chaperone protein that is abundantly expressed in primary human tumors (1). HSP60 has been shown to possess anti-apoptotic properties and serves a central role in tumor cell maintenance by stabilizing mitochondrial survivin expression and restraining p53 function (2). At present, the majority of studies on HSP60 focus on its intracellular anti-apoptotic functions in tumor cells (3-5).

An increasing number of studies have shown that endogenous HSP60 is upregulated in cells when cellular stress is increased and is released into the extracellular environment to induce an autoimmune response. This is particularly prevalent in activated microglia and in the myocardium of failing heart (6-10). HSP60 expression in colorectal cancer (CRC) tissue and the serum antibody titer to HSP60 is significantly higher in patients with CRC compared with healthy subjects (11). Extracellular HSP60 is a target of Toll-like receptor 4 (TLR-4), where the activation of which stimulates downstream signaling molecules, such as myeloid differentiation primary response 88 (MYD88) and NF- $\kappa \mathrm{B}$, resulting in an increase in the release inflammatory factors, such as inducible nitric oxide synthase (iNOS), IL-1 $\beta$, TNF- $\alpha$ and IL-6 (12). These inflammatory factors can promote tumor growth (13). Therefore, HSP60 inhibitors may serve as anticancer agents by inhibiting tumor growth, invasion and infiltration.

Curcumin (CCM) is a natural polyphenolic compound present in the rhizome of Curcuma longa and belongs to the family Zingiberaceae (14). An increasing number of experimental studies have revealed that $\mathrm{CCM}$ exhibits multiple biological effects and may serve as a potential protective factor of various diseases due to its anti-inflammatory, anti-oxidant and anti-apoptotic properties, whilst also possessing an excellent safety profile (15-17). The anticancer effects of CCM manifest due to its ability to induce growth arrest and apoptosis in various premalignant and malignant cells (18).

Several studies have shown the effects and mechanisms of CCM against human neuroglioma cells (19-21). CCM was shown to induce $\mathrm{G} 2 / \mathrm{M}$ cell cycle arrest and apoptosis in U87 cells by increasing forkhead box protein O1 expression (22), and was also reported to suppress tumor growth 
and angiogenesis in human glioma cells through modulation of VEGF/angiopoietin-2/thrombospondin-1 signaling $(23,24)$. Since inflammatory factors can enhance glioma growth, and CCM is an effective anti-inflammatory factor, it remains unknown whether CCM can exert its antitumor effects by inhibiting the inflammatory HSP60/TLR-4 signaling pathway.

The present study investigated the effects of CCM on the viability and invasive ability of neuroglioma U87 cells and determined whether the HSP60/TLR-4 signaling pathway is involved in this effect. The results demonstrated that CCM can exert its antitumor effects by inhibiting the inflammatory HSP60/TLR-4 signaling pathway. These findings suggested that CCM may be used as a potential therapy for the treatment of human glioma.

\section{Materials and methods}

Chemicals. The U87 cell line (glioblastoma of unknown origin) was purchased from The Cell Bank of Type Culture Collection of the Chinese Academy of Sciences. CCM was purchased from Sigma-Aldrich; Merck KGaA (cat. no. C1386). Antibodies against caspase-3 (cat. no. 9665), p53 (cat. no. 2524), MYD88 (cat. no. 4283) and TLR-4 (cat. no. 2219) were purchased from Cell Signaling Technology, Inc; anti-iNOS (cat. no. ab129372) and NF- $\mathrm{B}$ (cat. no. ab31481) antibodies were purchased from Abcam; antibodies against HSP60 (cat. no. API-SPA-901) and heat shock factor (HSF)-1 (cat. no. API-SPA-806), and a HSP60 ELISA kit (cat. no. ADI-EKS-600) were purchased from Enzo Life Sciences, Inc. and anti- $\beta$-actin antibody (cat. no. TA-09) was purchased from OriGene Technologies, Inc. IL-6 (cat. no. NOV-NR-E10276-1x96T), IL-1 $\beta$ (cat. no. EHC002b.96.10) and TNF- $\alpha$ (cat. no. ADI-901-099) ELISA kits were purchased from Neobioscience Technology Co., Ltd. BCA kits (cat. no. 23225) and ECL reagent (cat.no.32106) were purchased from Thermo Fisher Scientific, Inc. DMEM (cat. no. 220511) and FBS (cat. no. 16140071) were purchased from Gibco (Thermo Fisher Scientific, Inc.). Cell Counting Kit-8 (CCK-8; cat. no. BB-4202-1) was purchased from BestBio Science.

Cell culture. U87 cells were cultured in DMEM supplemented with $10 \% \mathrm{FBS}$ and maintained at $37^{\circ} \mathrm{C}$ in a humidified incubator with $5 \% \mathrm{CO}_{2}$. CCM was dissolved in DMSO (1 mM). Preliminary experiments were performed to determine the concentrations and time points of CCM treatment (data not shown). Cells were treated with different concentrations of CCM $(10,20,40,60$ or $80 \mu \mathrm{M})$ for $24 \mathrm{~h}$. The supernatant of culture medium and protein lysate of cells [lysed with $1 \mathrm{ml}$ RIPA buffer (Solarbio Life Sciences, cat. no. R0010)] with $1 \mu 1$ protease inhibitor, $5 \mu \mathrm{l}$ PMSF and $5 \mu \mathrm{l}$ phosphatase inhibitor) were collected for subsequent experiments. The morphological features of cell growth were observed using an inverted light microscope (magnification, x100 or 200).

Cell viability assay. A CCK-8 kit was used to assess the viability of cells following various treatments. A total of $5 \times 10^{4}$ cells/well were seeded into 96-well microtiter plates and treated with various concentrations of CCM. After $24 \mathrm{~h}, 10 \mu \mathrm{l}$ CCK-8 solution was added to each well, and cells were cultured for a further $2 \mathrm{~h}$. Absorbance was measured at a wavelength of $450 \mathrm{~nm}$ with an Immunoreader (Bio-Rad Laboratories, Inc.). Cell viability is presented as the percentage of the control value.

ELISA. ELISA kits were used to determine the quantity of TNF- $\alpha$, IL-6, IL-1 $\beta$ and HSP60 in culture medium according to the manufacturer's protocol. Absorbance was measured at a wavelength of $450 \mathrm{~nm}$ on a microplate reader (Bio-Rad Laboratories, Inc.).

Western blotting. A BCA kit was used to determine protein concentration. Equal amounts of protein $(20 \mu \mathrm{g})$ were resolved electrophoretically using $10 \%$ SDS-PAGE and transferred to a $0.45-\mu \mathrm{m}$ polyvinylidene difluoride membrane. The membrane blots were blocked with $5 \%$ milk in TBS-Tween-20 (0.1\% TBS-T) at room temperature (RT) for $1 \mathrm{~h}$ and incubated at $4^{\circ} \mathrm{C}$ overnight with antibodies against iNOS (1:200), TLR-4 (1:1,000), HSF-1 (1:1,000), NF-кB (1:1,000), HSP60 (1:1,000), p53 (1:1,000), Caspase-3 $(1: 2,000)$, MYD88 $(1: 1,000)$ or $\beta$-actin $(1: 1,000)$. After thoroughly washing the membrane with TBS-T buffer, they were incubated with HRP-conjugated anti-mouse (cat. no ZB-2305; OriGene Technologies, Inc.) or anti-rabbit (cat. no ZB-2301; OriGene Technologies, Inc.) secondary antibodies at RT for $2 \mathrm{~h}$. Signals were visualized using an ECL kit and the membranes were then exposed to X-ray films. The densitometry was analyzed by Image-Pro Plus software version 6.0 (Media Cybernetics, Inc.).

Statistical analysis. Data are presented as the mean \pm SEM. The data were analyzed using SPSS 19.0 (IBM Corp.). Statistical comparisons were performed using paired Student's t-test or one-way ANOVA followed by Dunnett's post hoc test. $\mathrm{P}<0.05$ was considered to indicate a statistically significant difference.

\section{Results}

Chemical structure of CCM and its effects on U87 cell viability. The chemical structure of CCM is [1,7-bis(4-hydroxy3-methoxyphenyl)-1,6-heptadiene-3, 5-dione] and is shown in Fig. 1A. To determine the effects of CCM on U87 cell viability, cck- 8 assays were performed. Cells were treated with various concentrations of CCM $(10,20,40,60$ or $80 \mu \mathrm{M})$ for $24 \mathrm{~h}$ and cell viability was assessed. The results showed that CCM treatment significantly inhibited the viability of U87 cells compared with the control group ( $\mathrm{P}<0.05$; Fig. 1B). Viability was normalized to cells that were incubated in media without CCM. The cell viability decreased with an increase in CCM concentration. An $\mathrm{IC}_{50}$ of $48.77 \mu \mathrm{M}$ was obtained by calculating the median lethal concentration. In order to prevent false positive results caused by low cell activity, $40 \mu \mathrm{M}$ CCM was chosen as the follow-up concentration for subsequent experiments.

CCM treatment affects cell morphology. The morphology of cells in the control group and CCM group (40 $\mu \mathrm{M}$ for $24 \mathrm{~h}$ ) was observed under an inverted microscope. As shown in Fig. 2, U87 cells in the control group (left panels) were polymorphous and the majority of them exhibited long fusiform 

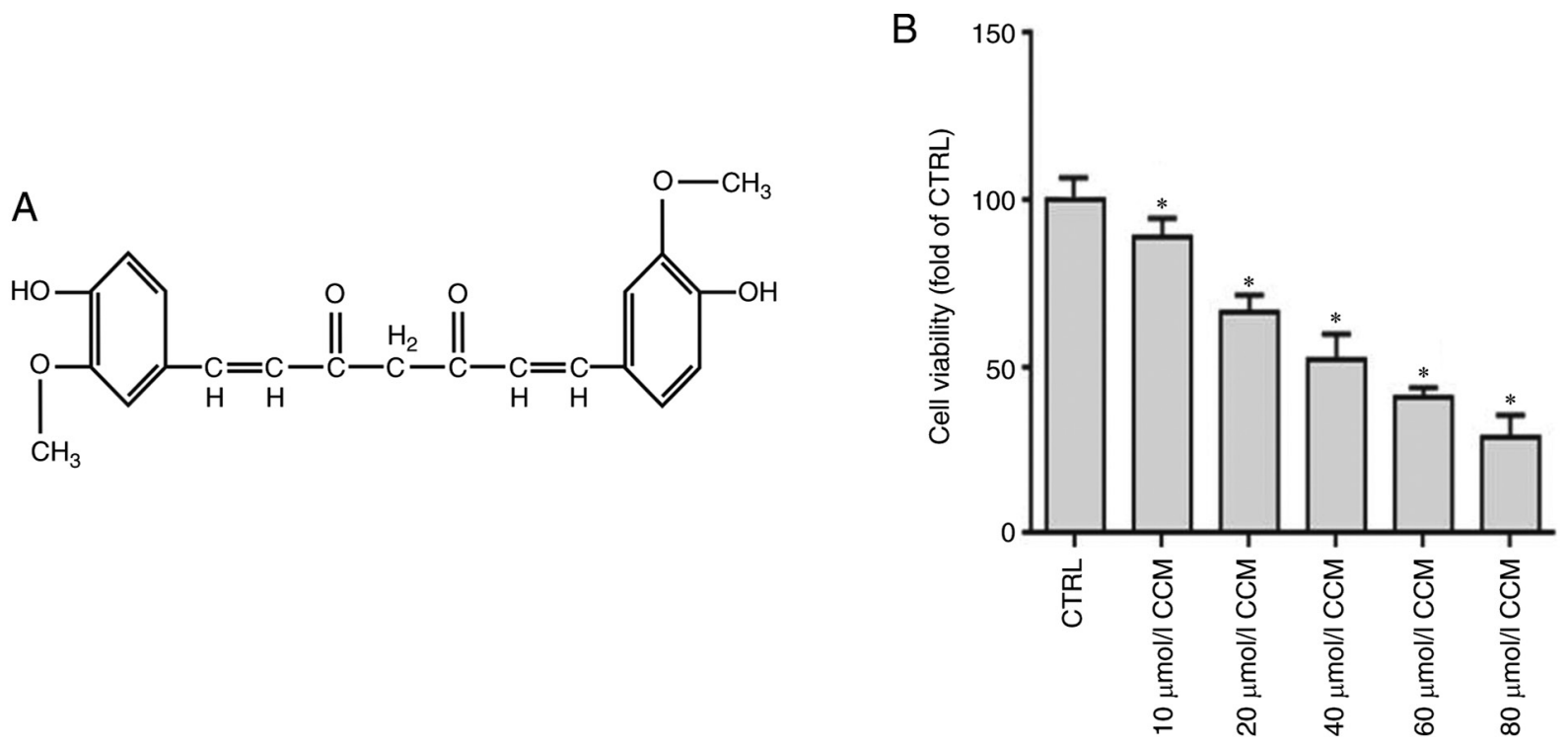

Figure 1. Chemical structure of CCM and its effects on U87 cell viability. (A) Chemical structure of CCM. (B) U87 cells were treated with different concentrations of CCM $(10,20,40,60$ or $80 \mathrm{uM})$, and cell proliferation was assessed using a Cell Counting Kit- 8 assay. Results are presented as the mean \pm standard error of the mean of three independent experiments. " $\mathrm{P}<0.05$ vs. CTRL group. CTRL, control; CCM, curcumin.

CTRL

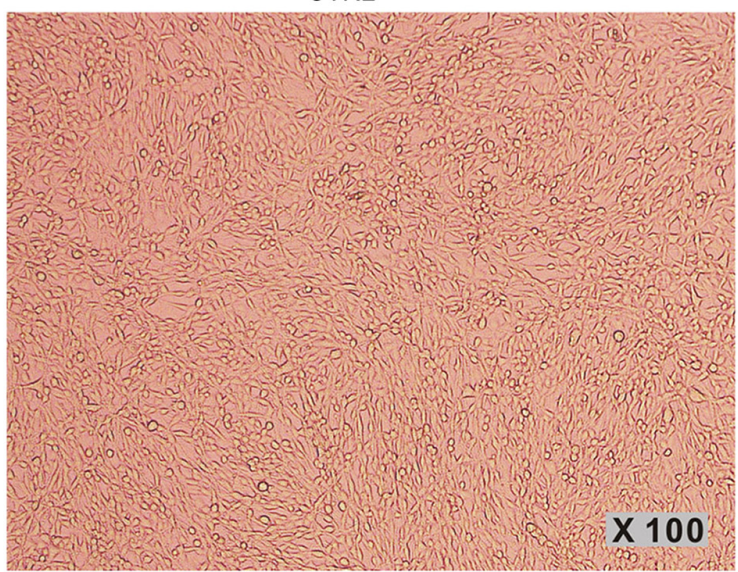

CTRL

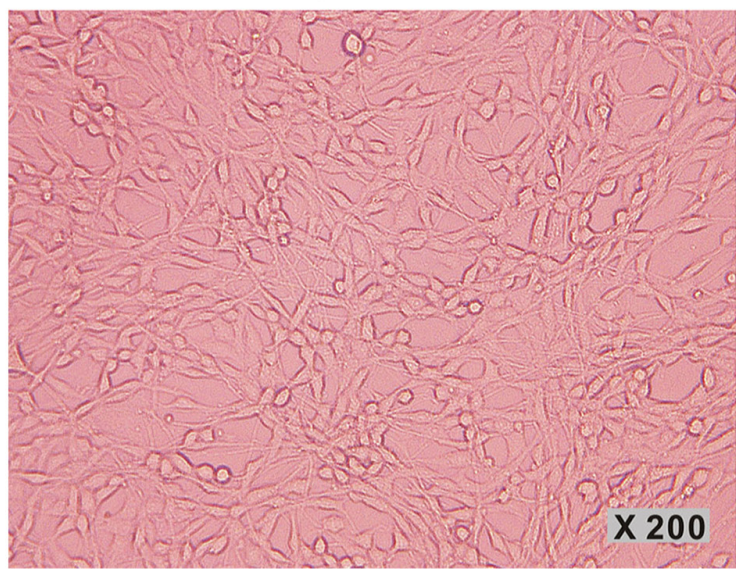

$\mathrm{U} 87+\mathrm{CCM}$

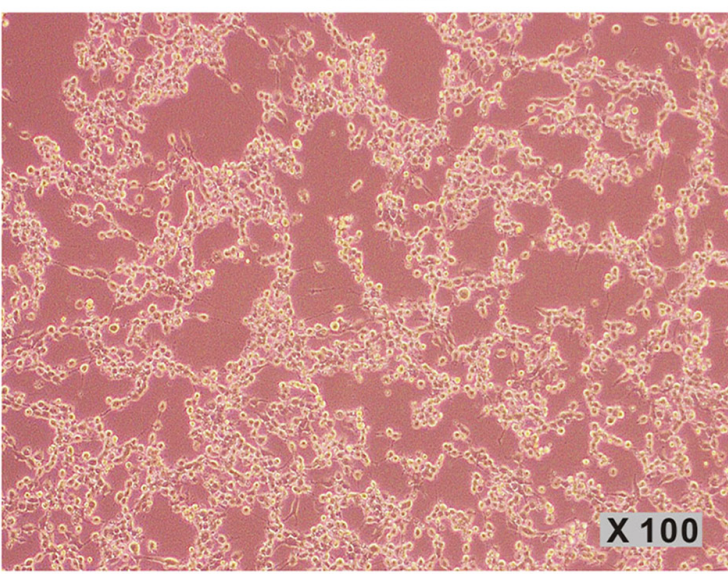

$\mathrm{U} 87+\mathrm{CCM}$

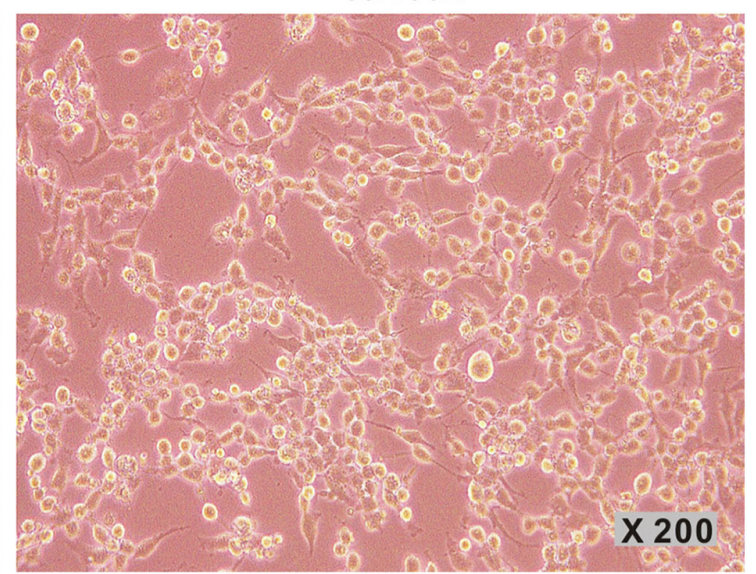

Figure 2. CCM treatment affects cell morphology. Magnification, x100 and 200. CCM, curcumin.

morphology. Cells were cross-linked and had several slender dendrites. Cells treated with CCM are shown in the right panels. Compared with the control group, the number of cells was notably lower, and the majority of cells exhibited a round morphology with shorter dendrites, showing signs of apoptosis. 
A
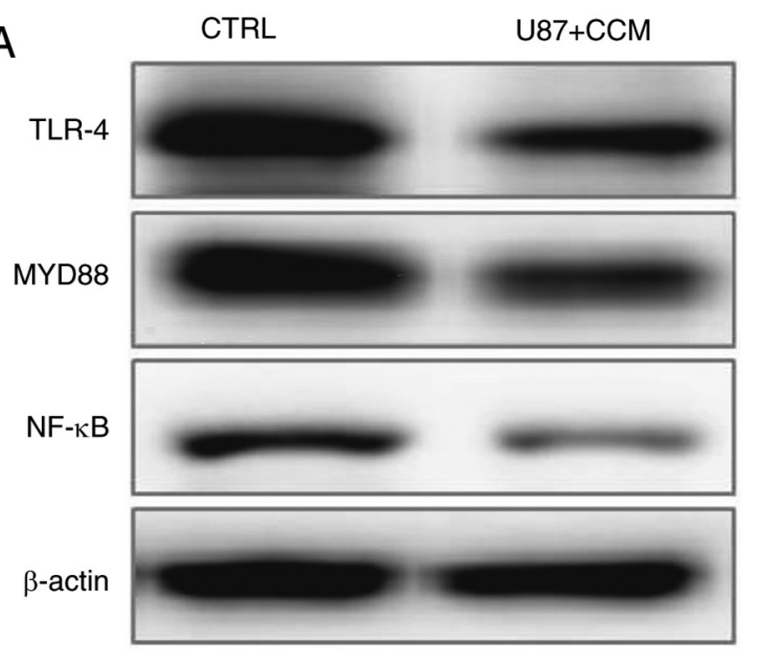

C

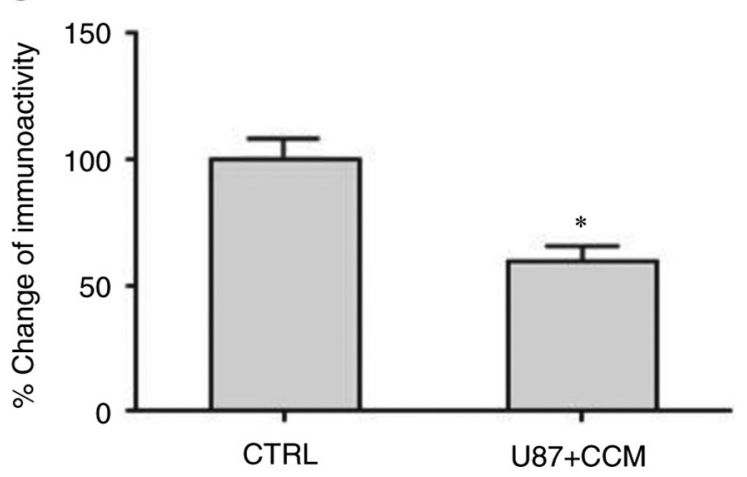

B

TLR-4

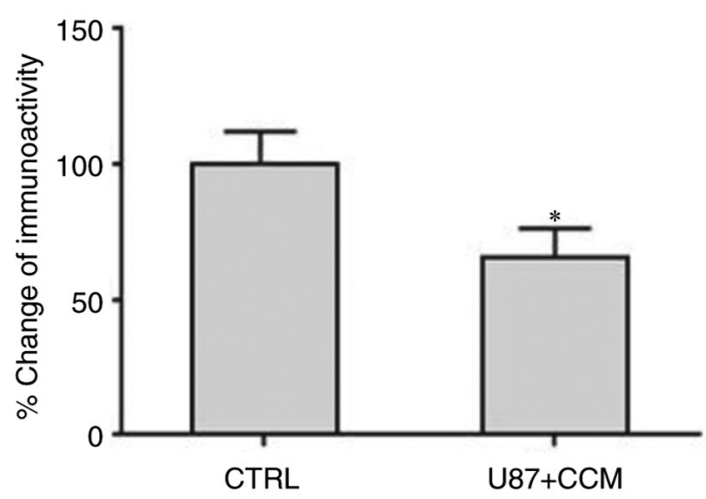

D

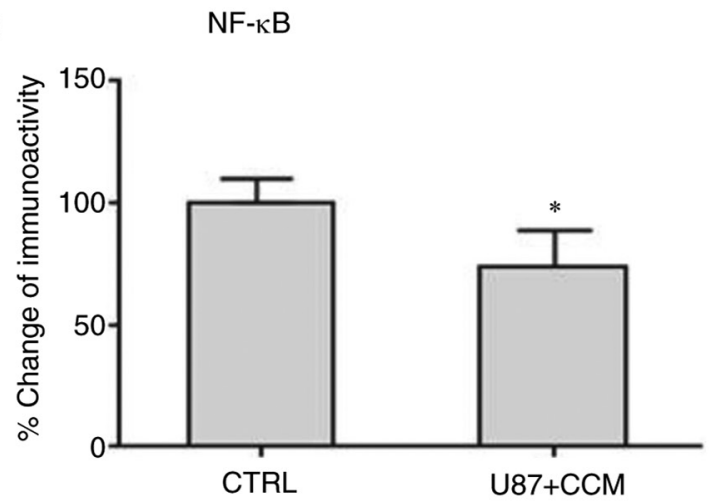

Figure 3. Expression levels of TLR-4, MYD88 and NF- $\kappa$ B were detected using western blotting. (A) Western blot results of TLR-4, MYD88 and NF- $\kappa$ B in CTRL and U87+CCM groups. $\beta$-actin was used as the internal reference. (B-D) Statistical analysis of A. Results are presented as the mean \pm standard error of the mean of three independent experiments. "P<0.05 vs. CTRL group. CTRL, control; CCM, curcumin; TLR-4, Toll-like receptor 4; MYD88, myeloid differentiation primary response 88 .

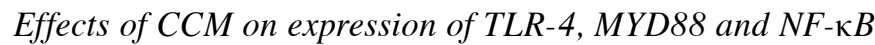
in U87 cells. The expression levels of TLR-4, MYD88 and $\mathrm{NF}-\kappa \mathrm{B}$ were detected using western blotting. As shown in Fig. 3, TLR-4, MYD88 and NF- $\mathrm{B}$ protein expression was significantly lower following CCM treatment compared with the controls.

CCM reduces the expression of HSP60 and HSF-1 and reduces $H S P 60$ release in $U 87$ cells. The expression levels of HSP60 and HSF-1, which can induce HSP60 expression, was detected by western blotting. As shown in Fig. 4, the levels of HSP60 and HSF-1 were significantly decreased in U87 cells treated with CCM compared with the control group. Extracellular HSP60 was measured by ELISA, and its release was significantly reduced in cells treated with CCM compared with controls.

Effects of CCM on inflammatory cytokine production in U87 cells. IL-1 $\beta$ and IL-6 secretion promotes tumor proliferation (25), whereas TNF- $\alpha$ can cause tumor cell apoptosis (26). Therefore, the levels of IL-1 $\beta$, IL- 6 and TNF- $\alpha$ in culture medium were measured using ELISA. As shown in Fig. 5, the levels of IL-1 $\beta$ and IL-6 significantly decreased in U87 cells treated with CCM, whereas TNF- $\alpha$ expression significantly increased compared with the control group. Thus, CCM may inhibit tumor cell proliferation by blocking IL- $1 \beta$ and IL- 6 release and promote tumor cell apoptosis by increasing TNF- $\alpha$ secretion.

Effects of CCM on the expression of iNOS, p53 and caspase-3 in U87 cells. The expression levels of iNOS, caspase-3 and p53 were detected by western blotting. The results showed that the levels of iNOS, which may promote malignant cell transformation and proliferation, was significantly reduced following treatment with CCM compared with controls (Fig. 6A and B). However, the expression levels of caspase-3 and p53, which can induce tumor apoptosis, significantly increased following CCM treatment compared with controls.

\section{Discussion}

The present study showed that treatment with $40 \mu \mathrm{M} \mathrm{CCM}$ effectively inhibited U87 glioma cell proliferation and invasion (data not shown) and induced U87 apoptosis. CCM reduced the expression of HSP60, HSF-1, TLR-4, MYD88 and $\mathrm{NF}-\kappa \mathrm{B}$, and increased the expression of the apoptosis-related proteins caspase-3 and tumor suppressor gene p53 in U87 cells. Additionally, expression of the proinflammatory factors IL-6, IL-1 $\beta$ and iNOS was decreased, and expression 
A
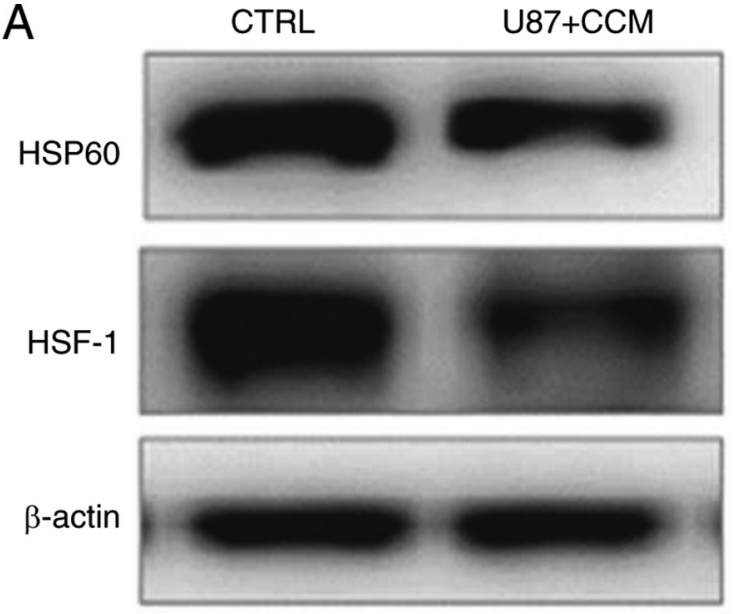

\section{C}

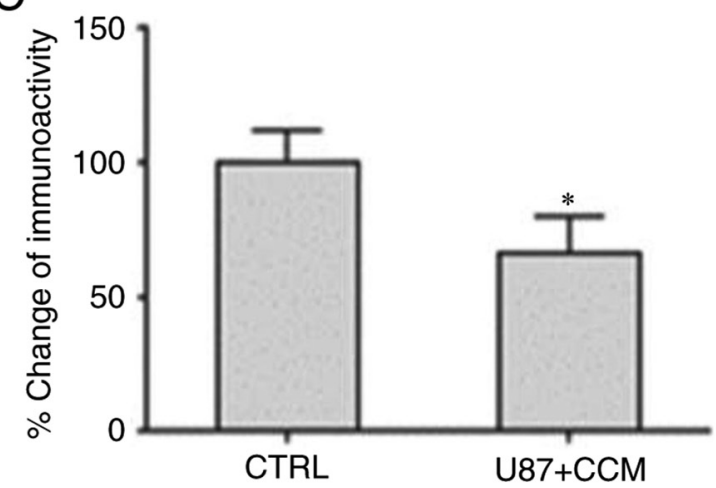

$B$
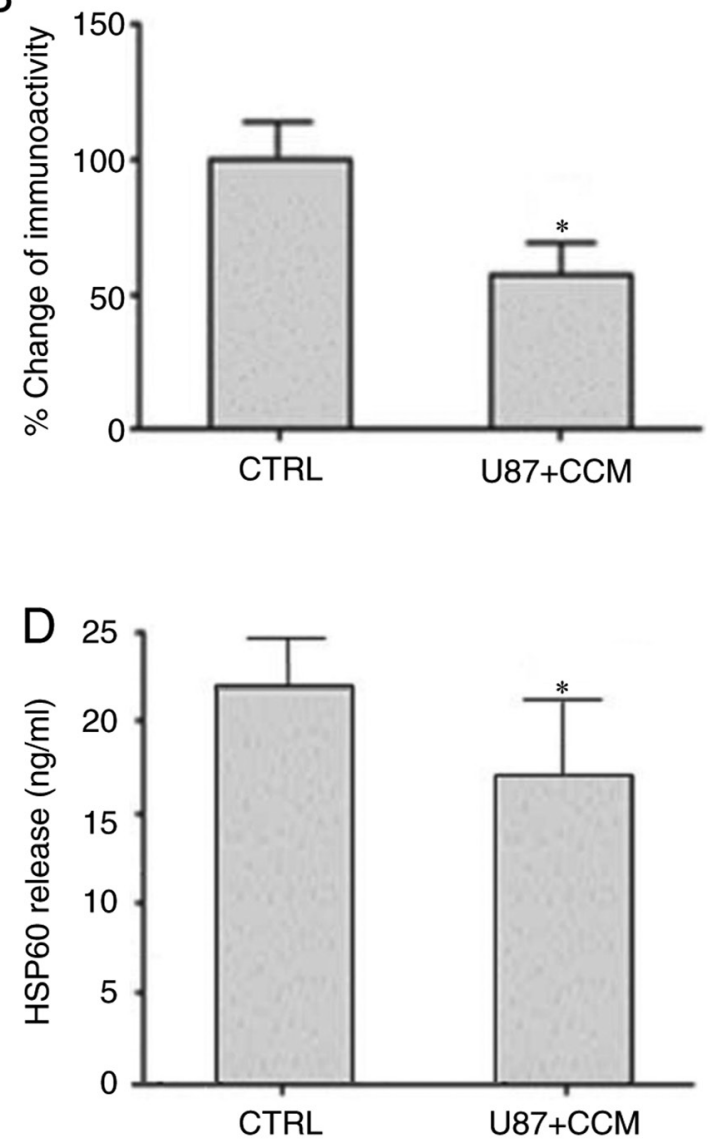

Figure 4. Expression levels of HSP60 and HSF1 in U87 cells, and extracellular release of HSP60 by U87 cells. (A) Expression levels of HSP60 and HSF1 were detected by western blotting, $\beta$-actin was used as the reference. Statistical analysis of the relative change in immunoactivity of (B) HSP60 and (C) HSF1 as a percentage. (D) Extracellular HSP60 levels in the two groups were detected using ELISA. Results are presented as the mean \pm standard error of the mean of three independent experiments. ${ }^{*}<0.05$ vs. CTRL group. CTRL, control; CCM, curcumin; HSP60, heat shock protein 60 ; HSF-1, heat shock factor-1.
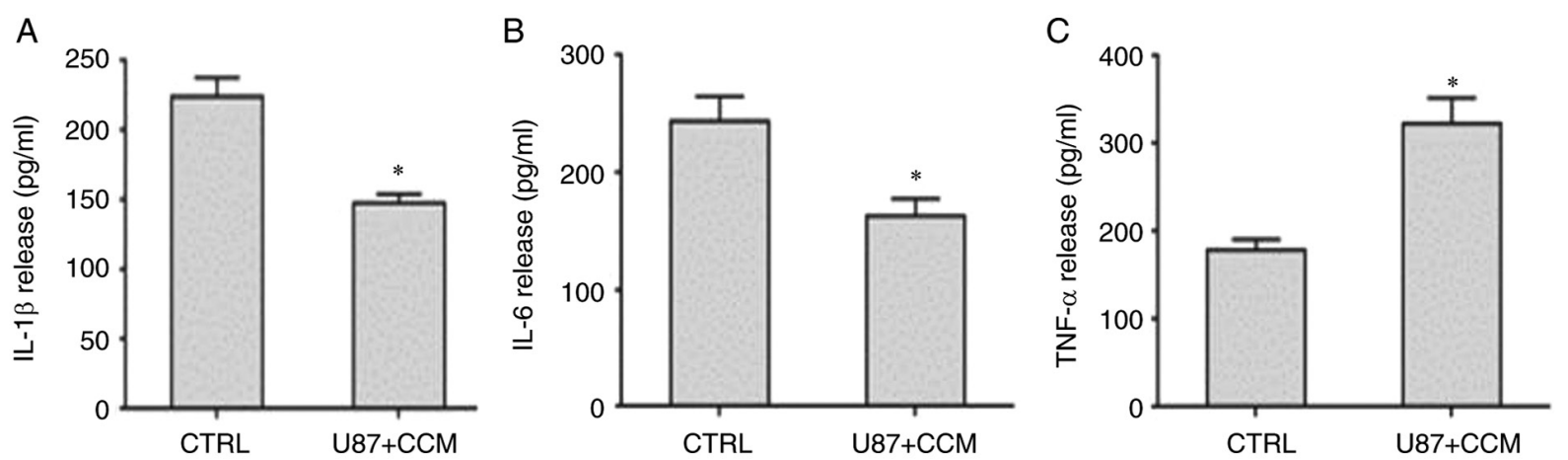

Figure 5. Effects of CCM on the production of inflammatory cytokines (IL-1 $\beta$, IL-6 and TNF- $\alpha$ ) in U87 cells. (A) ELISA of IL-1 $\beta$ level in the culture medium of U87 cells in CTRL and U87 + CCM groups. (B) ELISA of IL-6 level in the culture medium of U87 cells in CTRL and U87+CCM groups. (C) ELISA of TNF- $\alpha$ level in the culture medium of U87 cells in CTRL and U87 + CCM groups. Results are presented as the mean \pm standard error of the mean of three independent experiments. "P<0.05 vs. CTRL group. CTRL, control; CCM, curcumin; IL, interleukin; TNF, tumor necrosis factor.

of TNF- $\alpha$ was increased. To the best of our knowledge, the present study is the first to report that HSP60 participated in the anticancer activities of CCM in neuroglioma U87 cells via the HSP60/TLR-4/MYD88/NF- $\mathrm{BB}$ signaling pathway.

$\mathrm{CCM}$ is known to possess antitumor properties in several tumor cell lines and animal model experiments such as gastric carcinoma, tongue squamous cell carcinoma (27-29). The present study showed that $\mathrm{CCM}$ could significantly reduce the growth and invasion of U87 glioma cells. CCM inhibited the proliferation, invasion, angiogenesis and metastasis of different types of cancer via interactions with multiple cell signaling proteins, which differ based on the type of cancer (30). However, it remains unknown whether HSP60 is involved in the anticancer properties of CCM. 
A
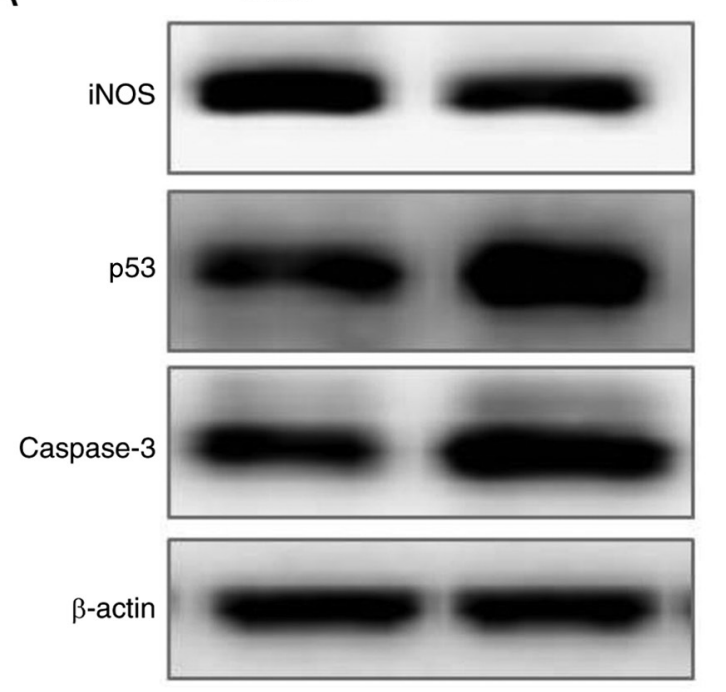

C

p53

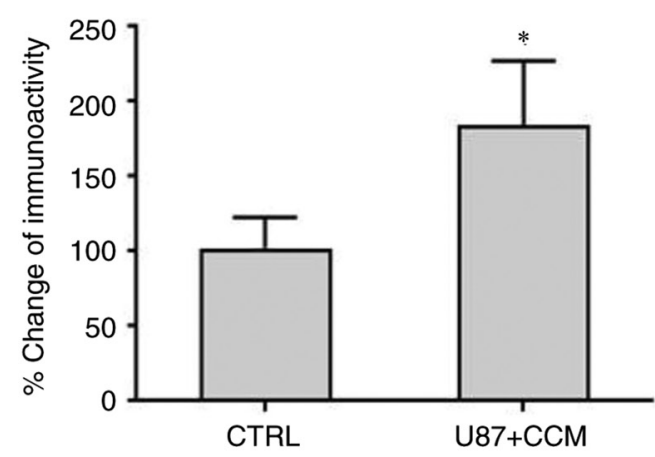

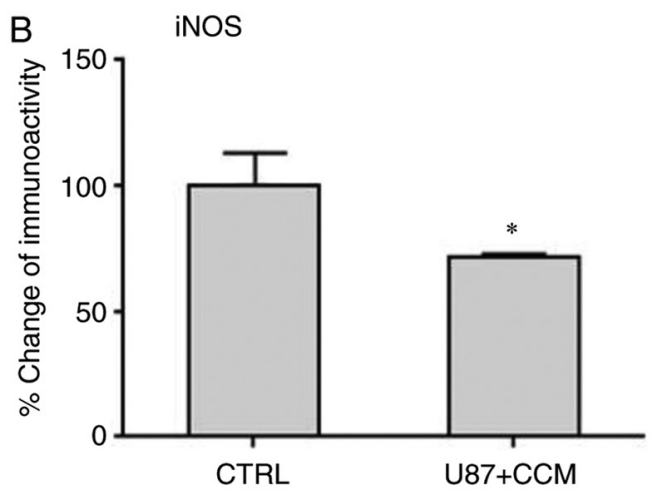

D Caspase-3

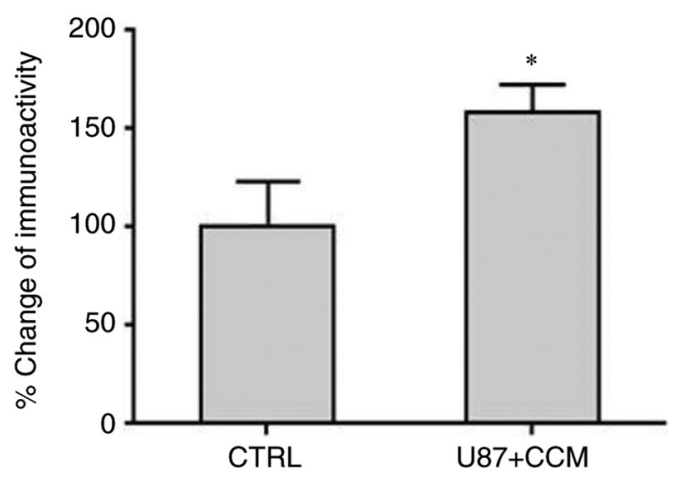

Figure 6. Expression levels of iNOS, p53 and Caspase 3. (A) iNOS, p53 and Caspase-3 levels were detected by western blotting. $\beta$-actin was used as a reference. Statistical analysis of the relative change in immunoactivity of (B) iNOS, (C) p53 and (D) caspase-3 as a percentage. Results are presented as the mean \pm standard error of the mean of three independent experiments. ${ }^{*} \mathrm{P}<0.05$ vs. CTRL group. CTRL, control; CCM, curcumin; iNOS, inducible nitric oxide synthase.

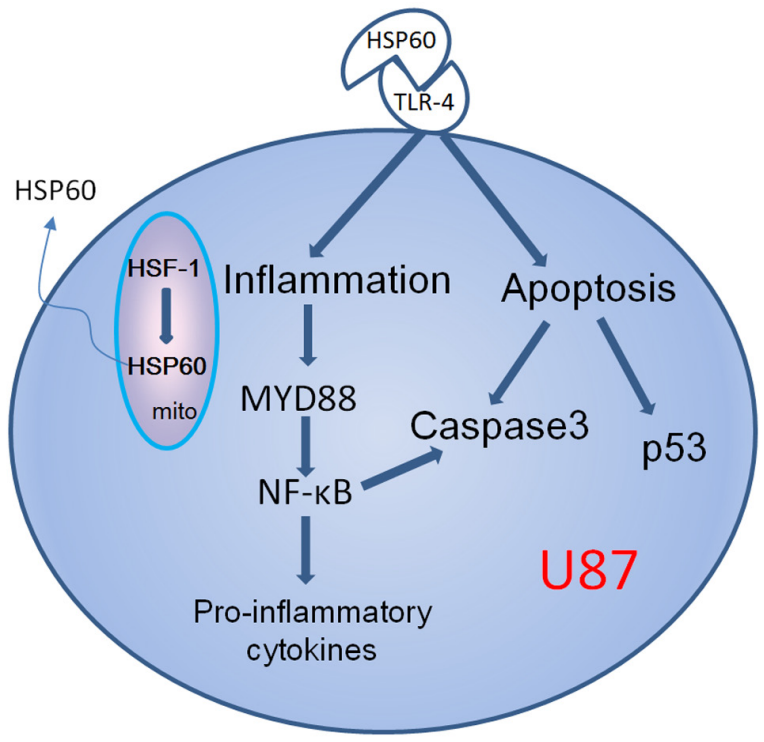

Figure 7. Schematic illustration showing the translocation of HSP60 from the mitochondria to the extracellular space of U87 cells and activation of the TLR-4 signaling pathway TLR-4, Toll-like receptor 4; MYD88, myeloid differentiation primary response 88 ; HSP60, heat shock protein 60; HSF-1, heat shock factor-1; mito, mitochondria.
HSP60 is a molecular chaperone. In addition to its chaperone role in assisting protein folding, HSP60 contributes to regulation of apoptosis and modulation of immune system activity, such as microglial activation-induced inflammation in the central nervous system $(31,32)$. Upregulated HSP60 expression has been detected in several malignant tumors, and its high expression has been shown to enhance cell survival by exhibiting an anti-apoptotic effect and through maintaining tumor cell growth (2). Therefore, inhibiting HSP60 expression may be a potential strategy for suppressing tumor growth. In the present study, HSP60 and its transcription factor HSF-1, which regulates the expression of HSP60 by binding to its promoter, were shown to be expressed in U87 cells. HSP60 was classically regarded as an intracellular protein, but in the last few years, considerable evidence has shown that it is expressed pericellularly and extracellularly $(33,34)$.

Our previous studies showed that intracellular HSP60 is released into the extracellular space, where it acts as a ligand for TLR-4 (6,7). TLR4 is expressed on a variety of immune and tumor cells, but its activation can have opposing effects, as it can either promote antitumor immunity or result in increased tumor growth and immunosuppression (35). 
The present study hypothesized that CCM may directly inhibit the expression of HSP60 or through inhibiting its transcription factor HSF-1 to suppress HSP60 gene expression, thereby decreasing HSP60 protein. As a mitochondrial protein, upon inflammation or stress, HSP60 can translocate to the cytosol and released to the extracellular space (9-10). Extracellular HSP60 is a ligand of TLR-4, where binding of HSP60 to TLR- 4 can result in the activation of one of two potential signaling pathways, which are either MYD88-dependent or MYD88-independent (Fig. 7). The present study showed that both TLR-4 and MYD88 were highly expressed in U87 cells, and their expression was reduced by CCM, indicating that inhibition of HSP60 expression by CCM resulted in downregulation of TLR-4 signaling via a MYD88-dependent pathway. TLR4/MYD88 expression levels were shown to be positively correlated with the metastasis of breast cancer cells (36). Highly expressed TLR4/MYD88 may be useful as a novel biomarker to evaluate the prognosis and treatment of patients with cancer.

NF- $\mathrm{kB}$ as a downstream signaling factor of TLR4/MYD88 and is a key factor in tumorigenesis, given its ability to regulate the expression and function of a number of genes involved in these processes (37). Constitutive activation of NF- $\kappa \mathrm{B}$ is a common feature of several human tumors, including gastric cancer, breast cancer and lung cancer, amongst others $(38,39)$. Aberrant NF- $\kappa$ B activity was also detected in human malignant astrocytoma cells (40). Therefore, inhibiting NF- $\kappa B$ should be effective in the prevention and treatment of cancer. In the present study, it was shown that curcumin could significantly decrease NF- $\kappa \mathrm{B}$ expression in U87 cells, suggesting that curcumin may suppress U87 cell growth by inhibiting NF- $\kappa \mathrm{B}$ activity.

When NF- $\mathrm{KB}$ is activated, the downstream corresponding proinflammatory cytokines IL-1 $\beta$ and IL- 6 are activated and secreted out of the cells, which can promote the proliferation of tumor cells (41). TLR-signaling and proinflammatory cytokines have been shown to act as drivers of tumorigenesis (42). CCM was shown to decrease IL- $1 \beta$ and IL- 6 levels in the present study. TNF- $\alpha$ is a member of the TNF/TNFR cytokine superfamily and serves an inhibitory role in the formation and growth of tumor cells (43). The results of the present study showed that TNF- $\alpha$ was upregulated by CCM, and this may contribute to the reduction in malignant progression of U87.

Apoptosis is a form of programmed cell death that results in the orderly and efficient removal of damaged cells, such as those resulting from DNA damage or during development. However, too little apoptosis occurs in cancers, resulting in malignant cells that will not die (44). The p53 tumor suppressor gene is a pivotal molecule mediating cell cycle arrest and apoptosis (45). Caspase-3 is a major mediator of apoptosis that is activated during cellular exposure to cytotoxic drugs, radiotherapy or immunotherapy, and is frequently used as a marker to assess the efficacy of cancer therapy (46). Apoptosis is regulated by p53-dependent signaling pathways, which regulate caspase-3 expression (47). The results of the present study showed that CCM significantly upregulated p53 and caspase-3 levels.

Proinflammatory factors that are secreted by tumor cells and the tumor microenvironment, whose expression may be driven by TLR4-mediated signals, induce angiogenesis and metastasis and promote tumor growth (48). They also provide signals necessary for the survival, accumulation and function of cancer cells (49). Therefore, the use of inhibitors of proinflammatory factors may prove beneficial for tumor therapy. TNF- $\alpha$ is a multifunctional cytokine, which serves key roles in apoptosis and cell survival as well as in inflammation and immunity, indicating its role as a double-edged sword (50). In the present study, CCM treatment increased TNF- $\alpha$ levels and decreased the levels of the proinflammatory cytokines IL-6, IL-1 $\beta$ and iNOS in U87 cells. This suggested that curcumin may inhibit tumor cell proliferation by blocking IL-1 $\beta$ and IL-6 release and promote tumor cell apoptosis by increasing TNF- $\alpha$ secretion.

Taken together, CCM may inhibit the invasion and growth of neuroglioma via the HSP60/TLR-4/MYD88/NF- $\kappa \mathrm{B}$ signaling pathway. Therefore, HSP60 may be a potential therapeutic target for treating neuroglioma. However, the lack of a proper control cell line is a limitation of the present study, and further studies should be performed to confirm these results.

\section{Acknowledgements}

Not applicable.

\section{Funding}

The present study was supported by the Ningxia Natural Science Foundation (grant nos. 2020AAC03143, 2020AAC03150), National Natural Science Foundation of China (grant nos. 82060223, 81571098 and 31560273) and Undergraduate Innovation and Entrepreneurship Training Program (S202010752032 and S202010752039).

\section{Availability of data and materials}

The datasets used and/or analyzed during the current study are available from the corresponding author on reasonable request.

\section{Authors' contributions}

FB and JW performed most of the experiments. XZ conducted some of the cell culture experiments. JX performed some of the molecular experiments. JG and ZM contributed to conception of the study, performed part of experiments and directed graduate students. JL and CZ contributed to acquisition and interpretation of data and revised figures. YZ acquired funding, performed some experiments, analyzed certain data, revised the manuscript and created Fig. 7. YW designed the project and gave final approval of the version to be published. YL designed the study, wrote the manuscript and analyzed part of data. All authors read and approved the final manuscript. FB and YW confirm the authenticity of all the raw data.

\section{Ethics approval and consent to participate}

Not applicable.

\section{Patient consent for publication}

Not applicable. 


\section{Competing interests}

The authors declare that they have no competing interests.

\section{References}

1. Ghosh AC, Dohi T, Kang BH and Altieri DC: Hsp60 regulation of tumor cell apoptosis. J Biol Chem 283: 5188-5194, 2008.

2. Huang YH and Yeh CT: Functional compartmentalization of HSP60-survivin interaction between mitochondria and cytosol in cancer Cells. Cells 9: 23, 2019.

3. Li XS, Xu Q, Fu XY and Luo WS: Heat shock protein 60 overexpression is associated with the progression and prognosis in gastric cancer. PLoS One 9: e107507, 2014

4. Desmetz C, Bibeau F, Boissière F, Bellet V, Rouanet P, Maudelonde T, Mangé A and Solassol J: Proteomics-based identification of HSP60 as a tumor-associated antigen in early stage breast cancer and ductal carcinoma in situ. J Proteome Res 7: 3830-3837, 2008.

5. Tsai YP, Yang MH, Huang CH, Chang SY, Chen PM, Liu CJ, Teng SC and Wu KJ: Interaction between HSP60 and beta-catenin promotes metastasis. Carcinogenesis 30: 1049-1057, 2009.

6. Zhang R, Li YH, Hou XL, Miao ZH and Wang Y: Neuroprotective effect of heat shock protein 60 on matrine-suppressed microglial activation. Exp Ther Med 14: 1832-1836, 2017.

7. Ding FJ, Li F, Li YH, Hou XL, Ma Y, Zhang N, Ma J, Zhang R, Lang B, Wang HY and Wang Y: HSP60 involved in neuroprotective effects of curcumin by suppressing microglia activation. Exp Ther Med 12: 823-828, 2016.

8. Cheng WJ, Li YH, Qi Q, Wang L, Ding FJ, Li F, Miao ZH, Yang SQ, Li GH, Wang J, et al: HSP60 is involved in the neuroprotective effects of Naloxone. Mol Med Rep 10: 2172-2176, 2014.

9. Wang Y, Chen L, Hagiwara N and Knowlton AA: Regulation of heat shock protein 60 and 72 expression in the failing heart. J Mol Cell Cardiol 48: 360-366, 2010.

10. Lin L, Kim SC, Wang Y, Gupta S, Davis B, Simon SI, Torre-Amione G and Knowlton AA: HSP60 in heart failure: Abnormal distribution and localization to lipid rafts. Am J Physiol Heart Circ Physiol 293: H2238-H2247, 2007.

11. Vocka M, Langer D, Fryba V, Petrtyl J, Hanus T, Kalousova M, Zima T and Petruzelka L: Novel serum markers HSP60, CHI3L1, and IGFBP-2 in metastatic colorectal cancer. Oncol Lett 18 6284-6292, 2019.

12. Ding F, Li Y, Hou X, Zhang R, Hu S and Wang Y: Oxymatrine inhibits microglia activation via HSP60-TLR4 signaling. Biomed Rep 5: 623-628, 2016.

13. Korniluk A, Koper O, Kemona H and Dymicka-Piekarska V: From inflammation to cancer. Ir J Med Sci 186: 57-62, 2017.

14. Kocaadam B and Şanlier N: Curcumin, an active component of turmeric (Curcuma longa), and its effects on health. Crit Rev Food Sci Nutr 57: 2889-2895, 2017.

15. Pluta R, Ułamek-Kozioł M and Czuczwar SJ: Neuroprotective and neurological/cognitive enhancement effects of curcumin after brain ischemia injury with Alzheimer's disease phenotype. Int J Mol Sci 19: 4002, 2018.

16. Rashid K, Chowdhury S, Ghosh S and Sil PC: Curcumin attenuates oxidative stress induced NFKB mediated inflammation and endoplasmic reticulum dependent apoptosis of splenocytes in diabetes. Biochem Pharmacol 143: 140-155, 2017.

17. Patel SS, Acharya A, Ray RS, Agrawal R, Raghuwanshi R and Jain P: Cellular and molecular mechanisms of curcumin in prevention and treatment of disease. Crit Rev Food Sci Nutr 60: 887-939, 2020

18. Devassy JG, Nwachukwu ID and Jones PJ: Curcumin and cancer: Barriers to obtaining a health claim. Nutr Rev 73: $155-165,2015$.

19. Panchal HD, Vranizan K, Lee CY, Ho J, Ngai J and Timiras PS: Early anti-oxidative and anti-proliferative curcumin effects on neuroglioma cells suggest therapeutic targets. Neurochem Res 33: 1701-1710, 2008.

20. Zhang Y, Tu L, Zhou X and Li B: Curcumin-mediated induction of apoptosis in human glioma CHME cells. Med Sci Monit Basic Res 24: 216-224, 2018.

21. Seyithanoğlu MH, Abdallah A, Kitiş S, Güler EM, Koçyiğit A, Dündar TT and Gündağ Papaker M: Investigation of cytotoxic, genotoxic, and apoptotic effects of curcumin on glioma cells. Cell Mol Biol (Noisy-le-grand) 65: 101-108, 2019.
22. Cheng C, Jiao JT, Qian Y, Guo XY, Huang J, Dai MC, Zhang L, Ding XP, Zong D and Shao JF: Curcumin induces G2/M arrest and triggers apoptosis via FoxO1 signaling in U87 human glioma cells. Mol Med Rep 13: 3763-3770, 2016.

23. Zhang Z, Li C, Tan Q, Xie CJ, Yang YY, Zhan WG, Han F, Sharma SH and Sharma A: Curcumin suppresses tumor growth and angiogenesis in human glioma cells through modulation of vascular endothelial growth factor/angiopoietin-2/thrombospondin-1 signaling. CNS Neurol Disord Drug Targets 16: 346-350, 2017.

24. Perry MC, Demeule M, Régina A, Moumdjian R and Béliveau R: Curcumin inhibits tumor growth and angiogenesis in glioblastoma xenografts. Mol Nutr Food Res 54: 1192-1201, 2010.

25. Cui G, Yuan A, Sun Z, Zheng W and Pang Z: IL-1 $\beta /$ IL-6 network in the tumor microenvironment of human colorectal cancer. Pathol Res Pract 214: 986-992, 2018.

26. van Horssen R, Ten Hagen TL and Eggermont AM: TNF-alpha in cancer treatment: Molecular insights, antitumor effects, and clinical utility. Oncologist 11: 397-408, 2006.

27. Deguchi A: Curcumin targets in inflammation and cancer. Endocr Metab Immune Disord Drug Targets 15: 88-96, 2015.

28. Wang XP, Wang QX, Lin HP and Chang N: Anti-tumor bioactivities of curcumin on mice loaded with gastric carcinoma. Food Funct 8: 3319-3326, 2017.

29. Liao F, Liu L, Luo E and Hu J: Curcumin enhances anti-tumor immune response in tongue squamous cell carcinoma. Arch Oral Biol 92: 32-37, 2018.

30. Kunnumakkara AB, Bordoloi D, Harsha C, Banik K, Gupta SC and Aggarwal BB: Curcumin mediates anticancer effects by modulating multiple cell signaling pathways. Clin Sci (Lond) 131: 1781-1799, 2017.

31. Sun Y, Zheng J, Xu Y and Zhang X: Paraquat-induced inflammatory response of microglia through HSP60/TLR4 signaling. Hum Exp Toxicol 37: 1161-1168, 2018.

32. Jakic B, Buszko M, Cappellano G and Wick G. Elevated sodium leads to the increased expression of HSP60 and induces apoptosis in HUVECs. PLoS One 12: e0179383, 2017.

33. Juwono J and Martinus RD: Does Hsp60 provide a link between mitochondrial stress and inflammation in diabetes mellitus? J Diabetes Res 2016: 8017571, 2016.

34. Caruso Bavisotto C, Cappello F, Macario AJL, Macario de EC, Logozzi M, Fais S and Campanella C: Exosomal HSP60: A potentially useful biomarker for diagnosis, assessing prognosis, and monitoring response to treatment. Expert Rev Mol Diagn 17: 815-822, 2017.

35. Shetab Boushehri MA and Lamprecht A: TLR4-based immunotherapeutics in cancer: A review of the achievements and shortcomings. Mol Pharm 15: 4777-4800, 2018.

36. Chen X, Zhao F, Zhang H, Zhu Y, Wu K and Tan G: Significance of TLR4/MYD88 expression in breast cancer. Int J Clin Exp Pathol 8: 7034-7039, 2015.

37. Jing X, Tian Z, Gao P, Xiao H, Qi X, Yu Y, Ding X, Yang L and Zong L: HBsAg/B2GPI activates the NF- $\mathrm{KB}$ pathway via the TLR4/MyD88/IкB $\alpha$ axis in hepatocellular carcinoma. Oncol Rep 40: 1035-1045, 2018.

38. Sokolova $\mathrm{O}$ and Naumann $\mathrm{M}$ : NF- $\mathrm{NB}$ signaling in gastric cancer Toxins (Basel) 9: 119, 2017.

39. Liu B, Sun L, Liu Q, Gong C, Yao YD, Lv XB, Lin L, Yao HR, Su FX, Li DS, et al: A cytoplasmic NF- $\kappa \mathrm{B}$ interacting long noncoding RNA blocks I $\mathrm{B}$ phosphorylation and suppresses breast cancer metastasis. Cancer Cell 27: 370-381, 2015.

40. Friedmann-Morvinski D, Narasimamurthy R, Xia Y, Myskiw C, Soda Y and Verma IM: Targeting NF- $\mathrm{KB}$ in glioblastoma: A therapeutic approach. Sci Adv 2: e1501292, 2016.

41. Martins GR, Gelaleti GB, Moschetta MG, Maschio-Signorini LB and Zuccari DA: Proinflammatory and anti-inflammatory cytokines mediated by NF- $\kappa \mathrm{B}$ factor as prognostic markers in mammary tumors. Mediators Inflamm 2016: 9512743, 2016.

42. Das S, Shapiro B, Vucic EA, Vogt S and Bar-Sagi D: Tumor cell-derived ill $\beta$ promotes desmoplasia and immune suppression in pancreatic cancer. Cancer Res 80: 1088-1101, 2020.

43. Hehlgans T and Männel DN: The TNF-TNF receptor system. Biol Chem 383: 1581-1585, 2002.

44. Roos WP, Thomas AD and Kaina B: DNA damage and the balance between survival and death in cancer biology. Nat Rev Cancer 16: 20-33, 2016

45. Chen J: The cell-cycle arrest and apoptotic functions of p53 in tumor initiation and progression. Cold Spring Harb Perspect Med 6: a026104, 2016. 
46. Galluzzi L, Kepp O and Kroemer G: Caspase-3 and prostaglandins signal for tumor regrowth in cancer therapy. Oncogene 31: 2805-2808, 2012.

47. Sam MR and Pourpak RS: Regulation of p53 and survivin by prodigiosin compound derived from Serratia marcescens contribute to caspase-3-dependent apoptosis in acute lymphoblastic leukemia cells. Hum Exp Toxicol 37: 608-617, 2018.

48. Oblak A and Jerala R: Toll-like receptor 4 activation in cancer progression and therapy. Clin Dev Immunol 2011: 609579, 2011.
49. Sawa-Wejksza K and Kandefer-Szerszeń M: Tumor-associated macrophages as target for antitumor therapy. Arch Immunol Ther Exp (Warsz) 66: 97-111, 2018.

50. Lai WY, Wang JW, Huang BT, Lin EP and Yang PC: A novel TNF- $\alpha$-targeting aptamer for TNF- $\alpha$-mediated acute lung injury and acute liver failure. Theranostics 9: 1741-1751, 2019.

(i) (2) This work is licensed under a Creative Commons Attribution-NonCommercial-NoDerivatives 4.0 International (CC BY-NC-ND 4.0) License. 